\title{
Treatment of Neuroblastoma Cells with Inhibitors of Protein Disulfide Isomerase Upregulates NQ01 Activity
}

Dennis Özcelik

Department of Drug Design and Pharmacology, University of Copenhagen, Universitetsparken 2, 2100 Copenhagen, Denmark

Email: dennis.ozcelik@sund.ku.dk

\section{Keywords}

Neurodegeneration, chaperone, microarray expression profile, redox regulation, neuropharmacology, small molecules 
A

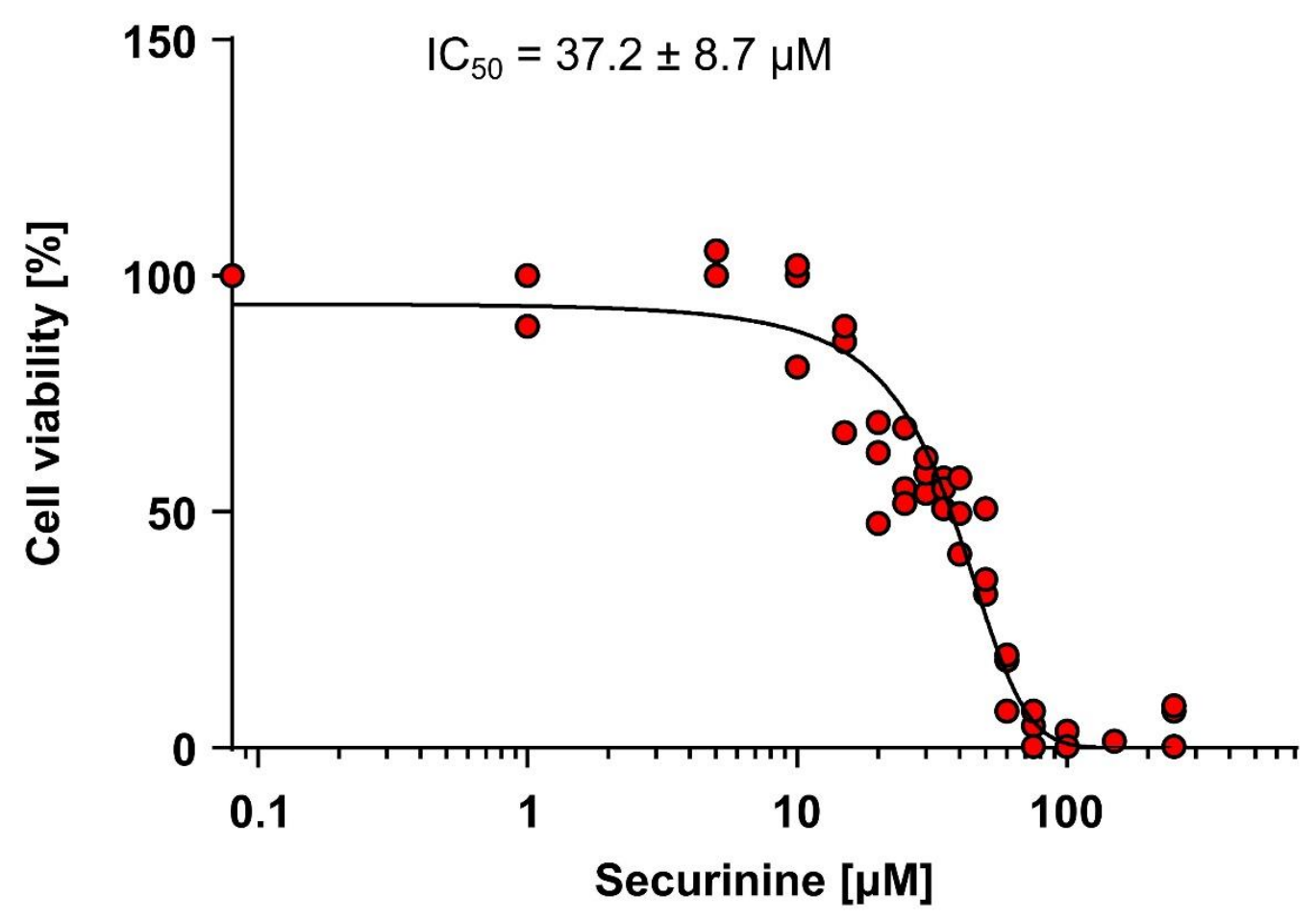

B

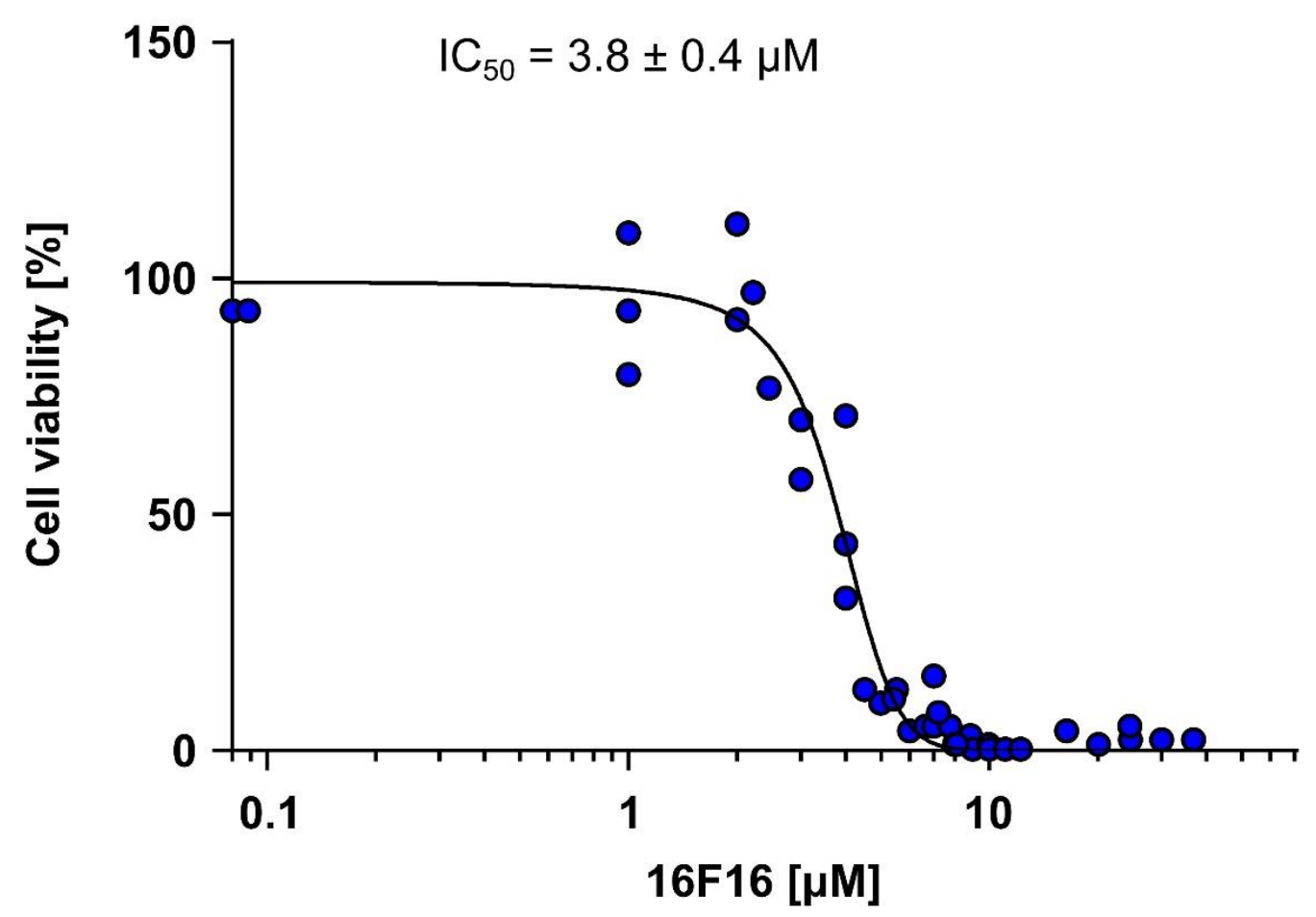

Figure S1. SH-SY5Y neuroblastoma cells were incubated for $24 \mathrm{~h}$ with increasing concentrations of securinine (A) or 16F16 (B), respectively. Each solid circle represents a single, independent biological experiment. 
A

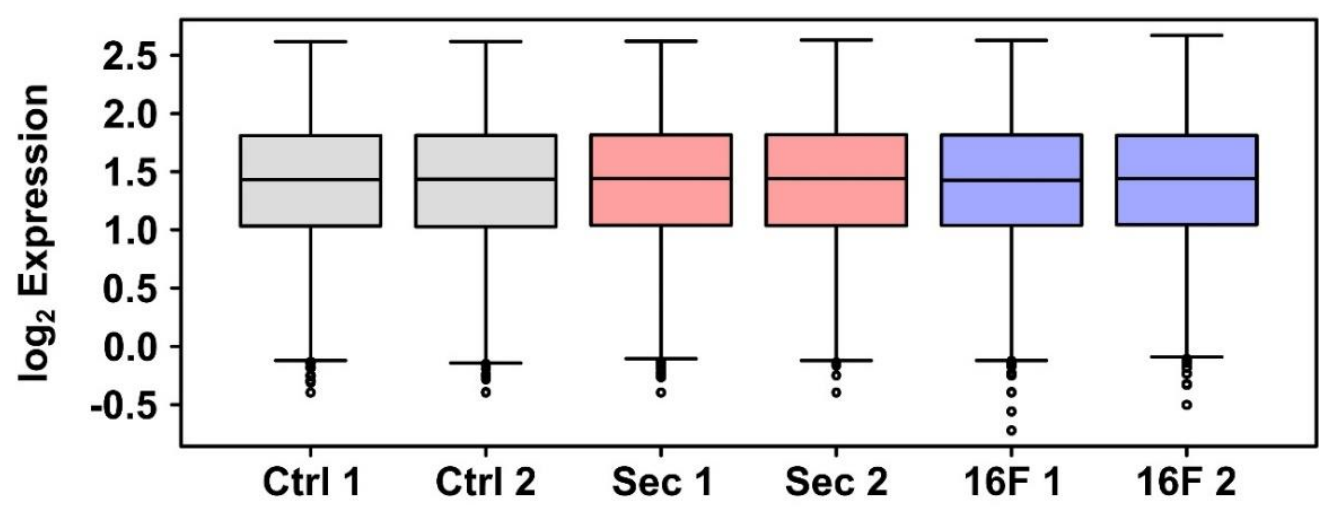

B
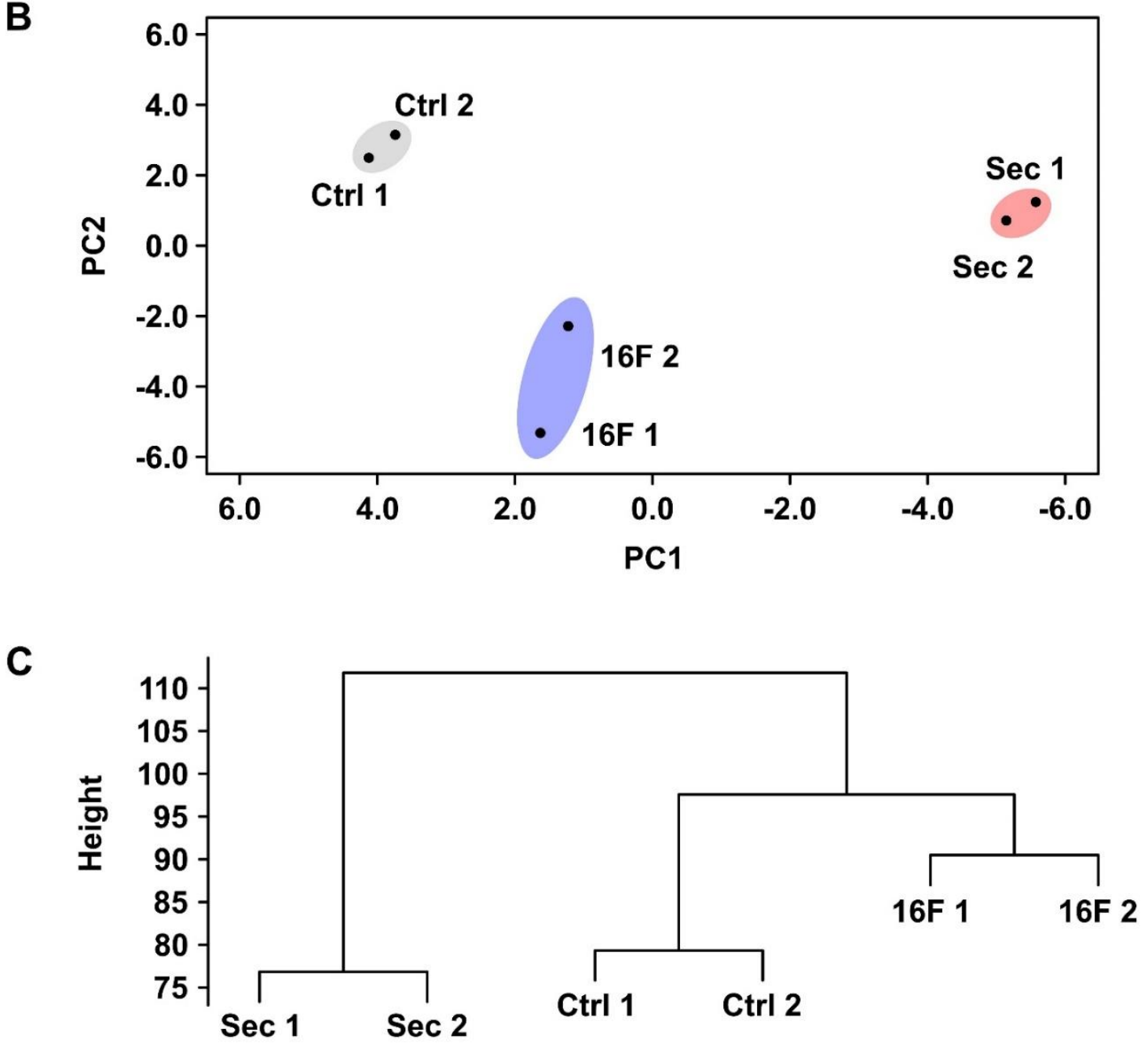

Figure S2. (A) Gene expression signals of individual microarrays after normalization. (B) Principal component analysis (PCA) shows similarities in gene expression profiles. Each black circle in the similarity matrix represents an individual microarray. (C) Dendrogram represents global hierarchical clustering of microarray data. 
Supplementary Information
A Securinine
downregulated
upregulated
total
unfiltered

$$
7057
$$
1159
5786
$\mathrm{FC}>1.5$
$\mathrm{FC}>2.0$
356
812
1971
552

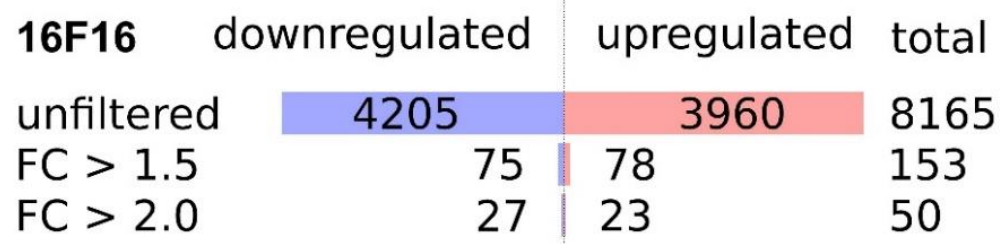

B

(552)

upregulated: 17

downregulated: 19
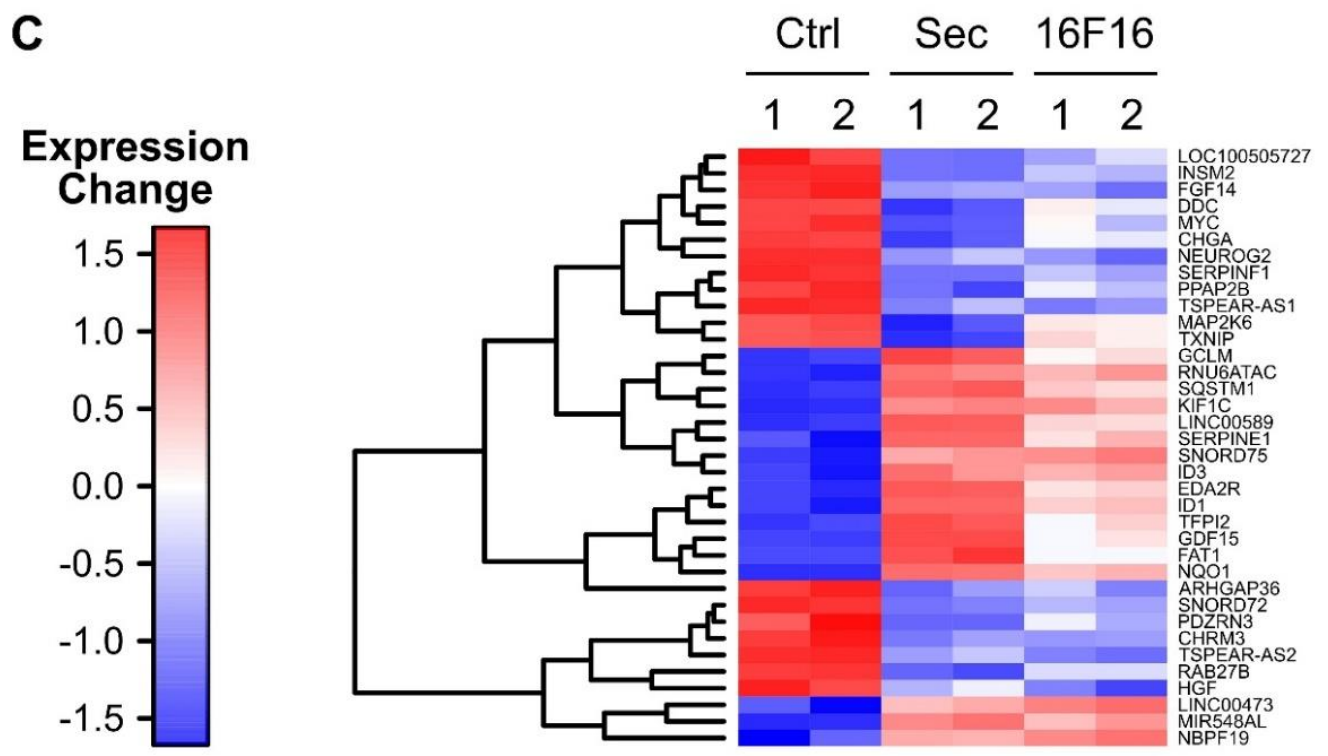

Figure S3. (A) Scheme depicts numbers of DEGs identified in the microarray data sets of samples treated with securinine (top) or 16F16 (bottom) before filtering and after selecting for 1.5 -fold change or 2-fold change in gene expression levels. (B) Venn diagram depicts overlapping DEGs between treatments with securinine and 16F16. (C) Heatmap and hierarchical clustering of 36 DEGs (cut-off $>2$-fold change) identified in all six microarray data sets. 


\section{A}

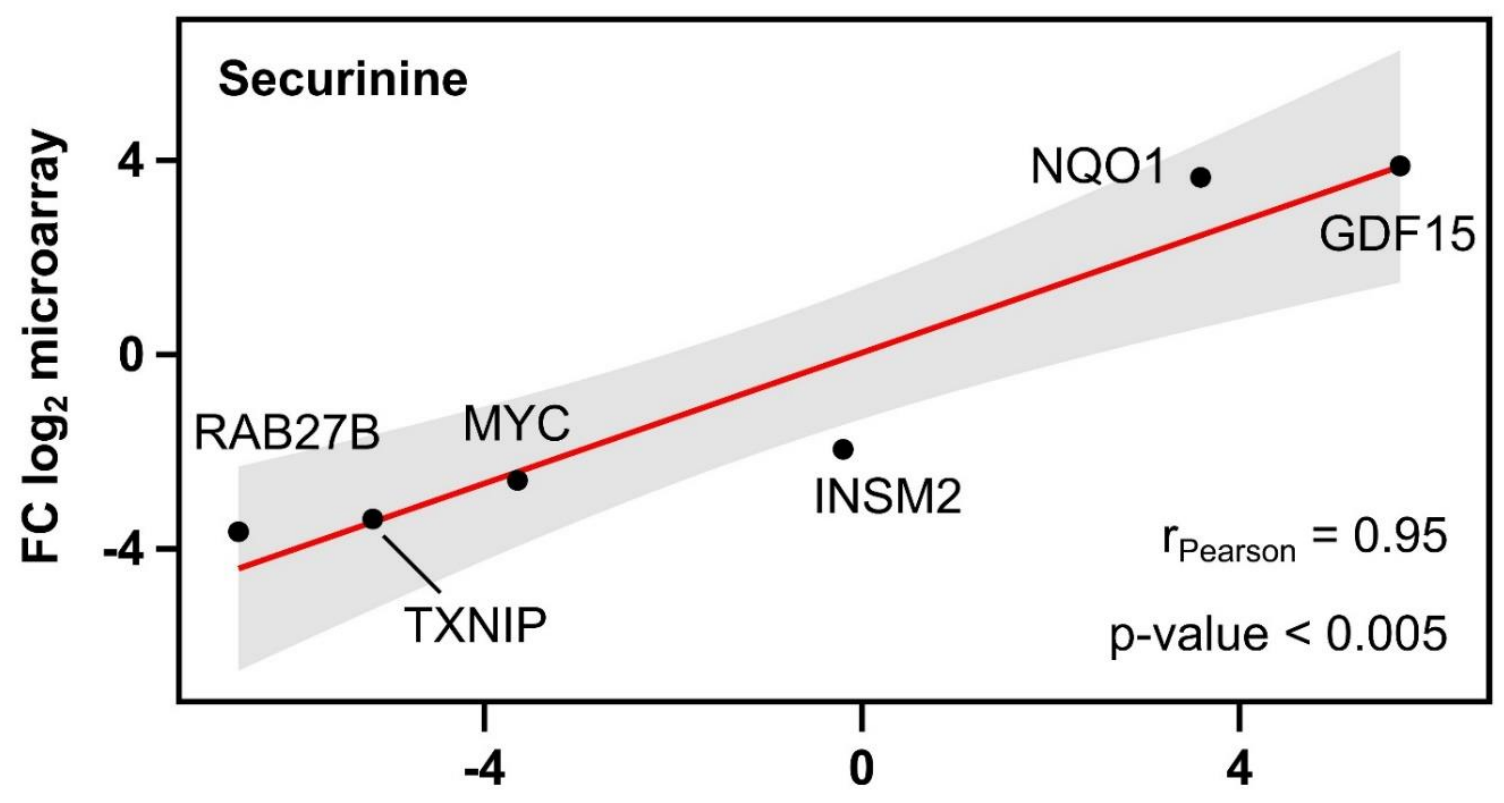

FC $\log _{2}$ qRT-PCR

B

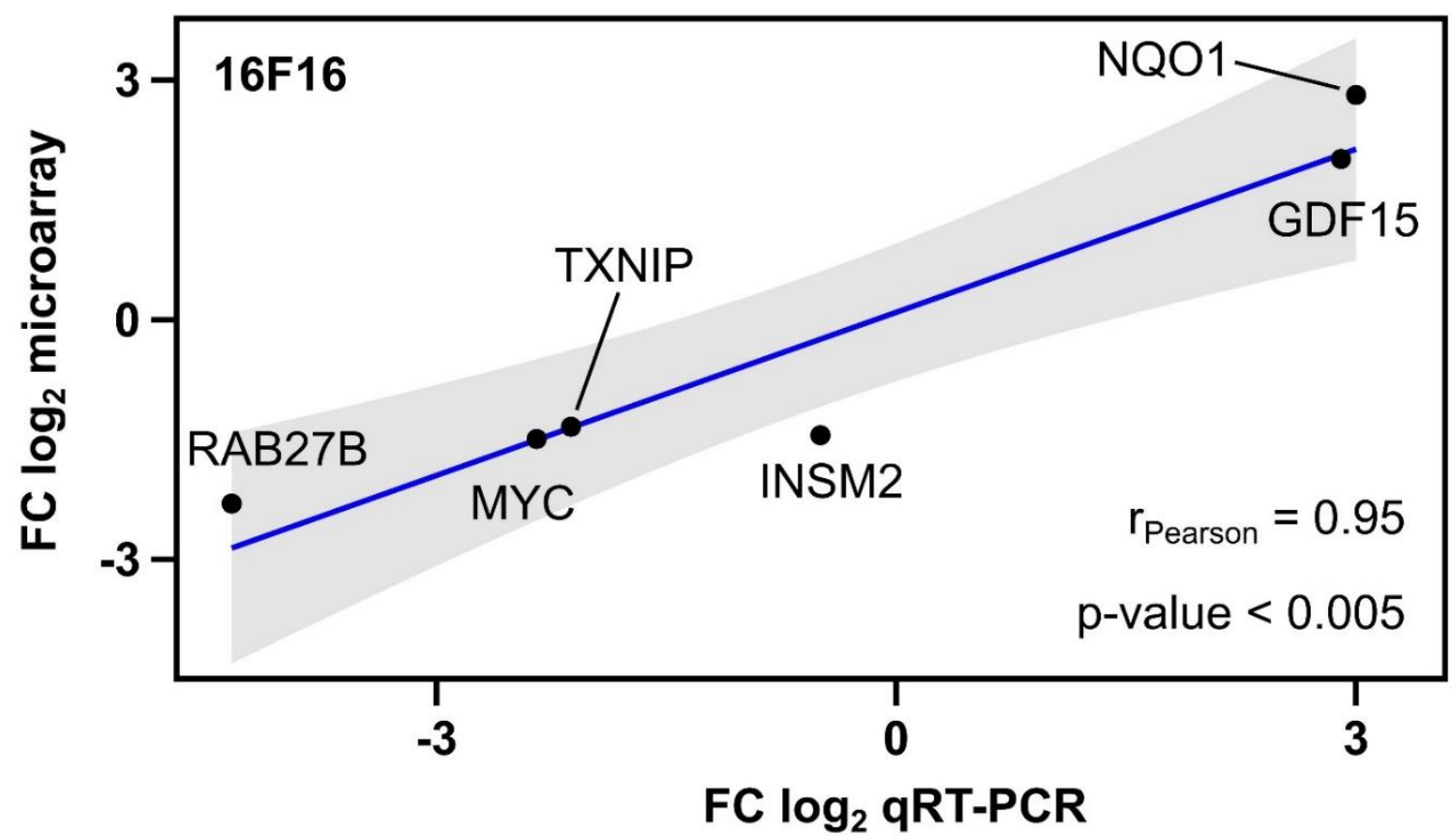

Figure S4. Pearson's product-moment correlation coefficient was used to analyze the relationship between gene expression changes determined by microarray and qRT-PCR for either securinine treatment $(\mathbf{A})$ or $16 \mathrm{~F} 16$ treatment $(\mathbf{B})$. A linear regression curve is shown in red (for securinine) or blue (for 16F16); the $95 \%$ confidence interval is depicted as a grey area. 


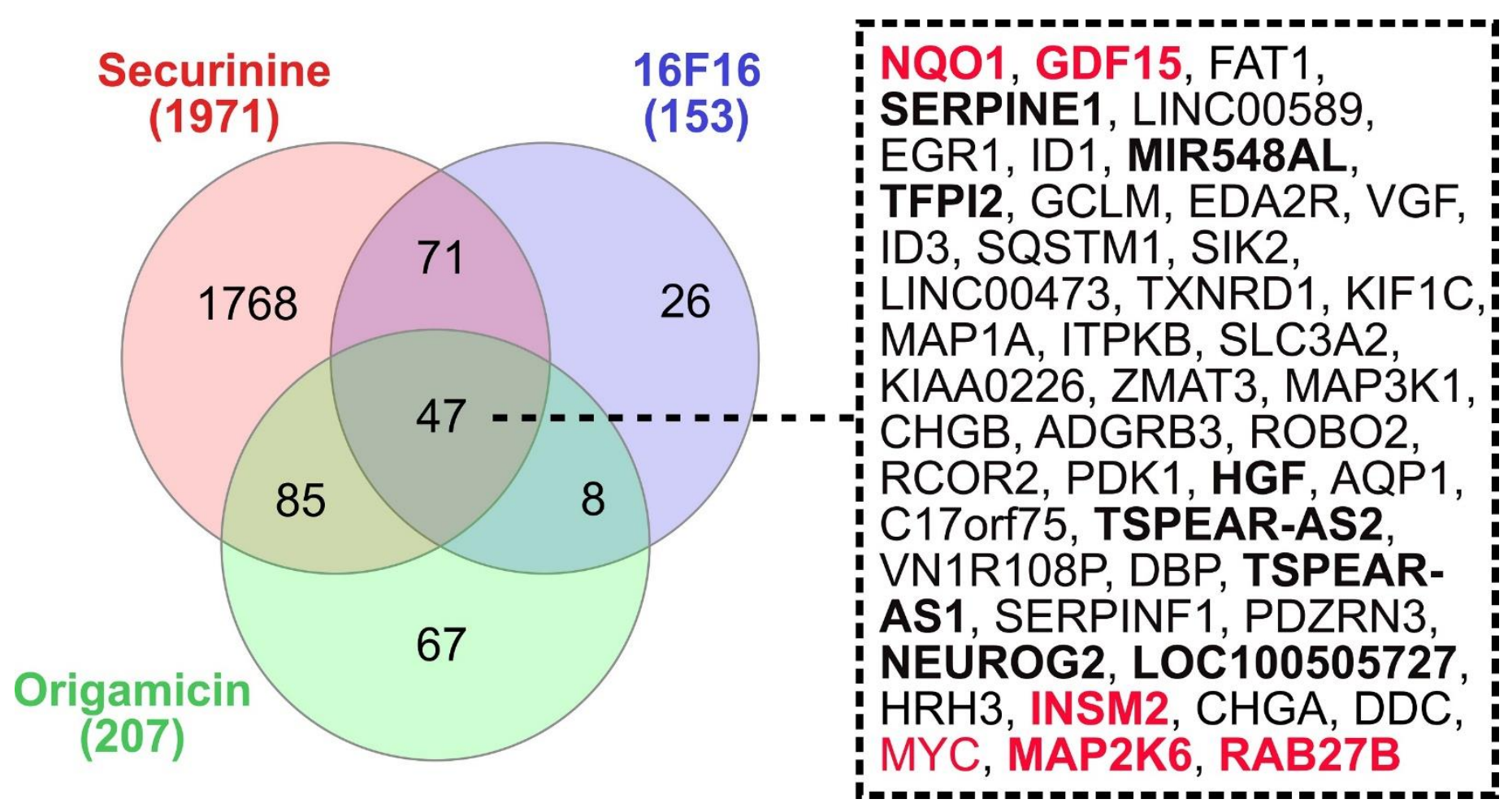

Figure S5. Differentially expressed genes (DEGs) in SH-SY5Y cells upon treatment with the PDI inhibitors of this study — securinine and 16F16 —and origamicin (another study ${ }^{1}$ ) The Venn diagram shows DEGs with at least 1.5 -fold change. The box on the right present the DEGs commonly found in all three treatments. A fold-change of at least 2 is indicated in bold. DEGs that were validated experimentally are highlighted in red. 


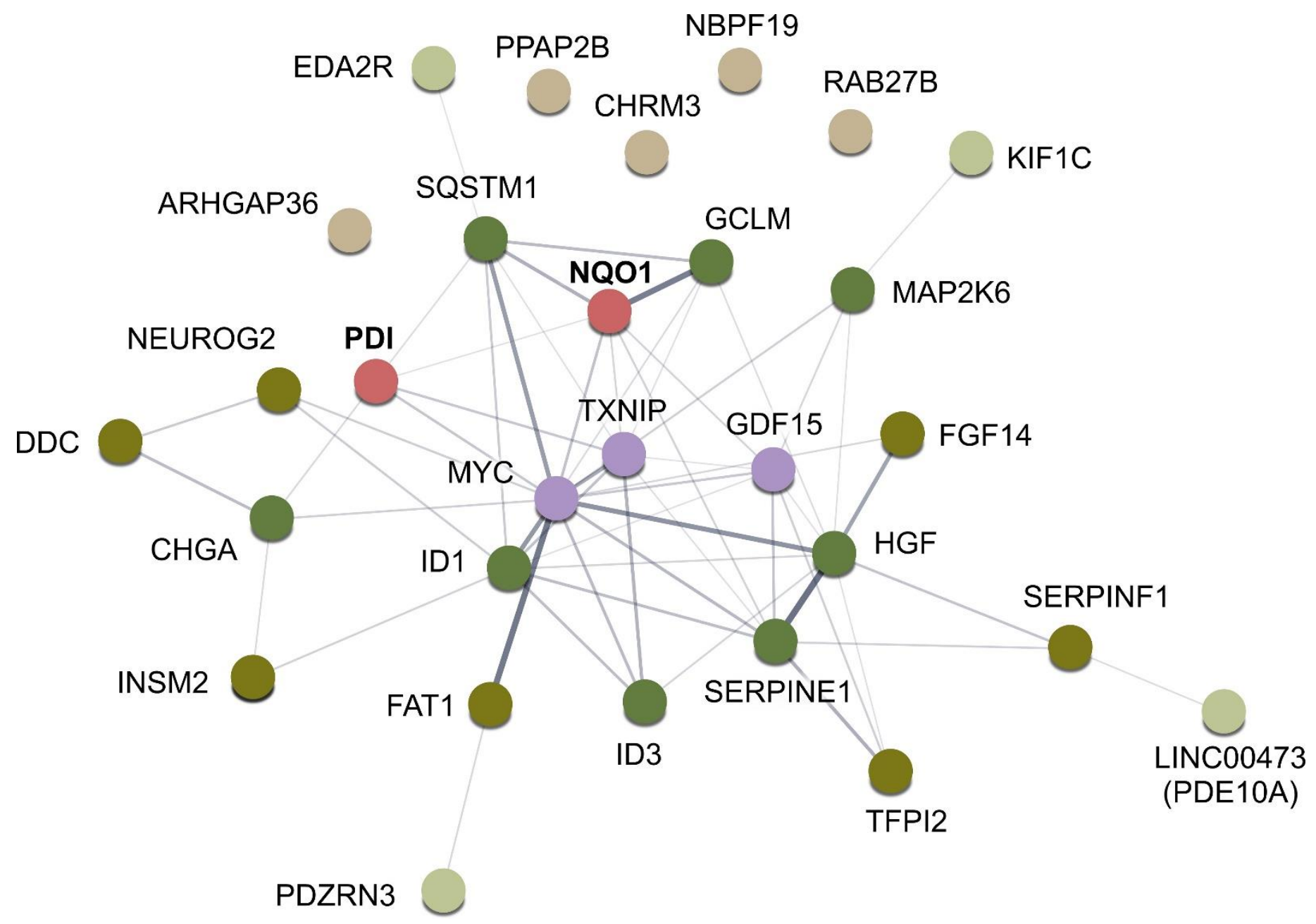

Figure S6. Prediction of protein-protein interactions of commonly identified DEGs in SH-SY5Y cells upon treatment with securinine, and 16F16 using the STRING database ${ }^{2}$. The interaction map shows DEGs with at least 2-fold change. Line thickness indicates strength of data support with a minimum interaction score of 0.200 . 


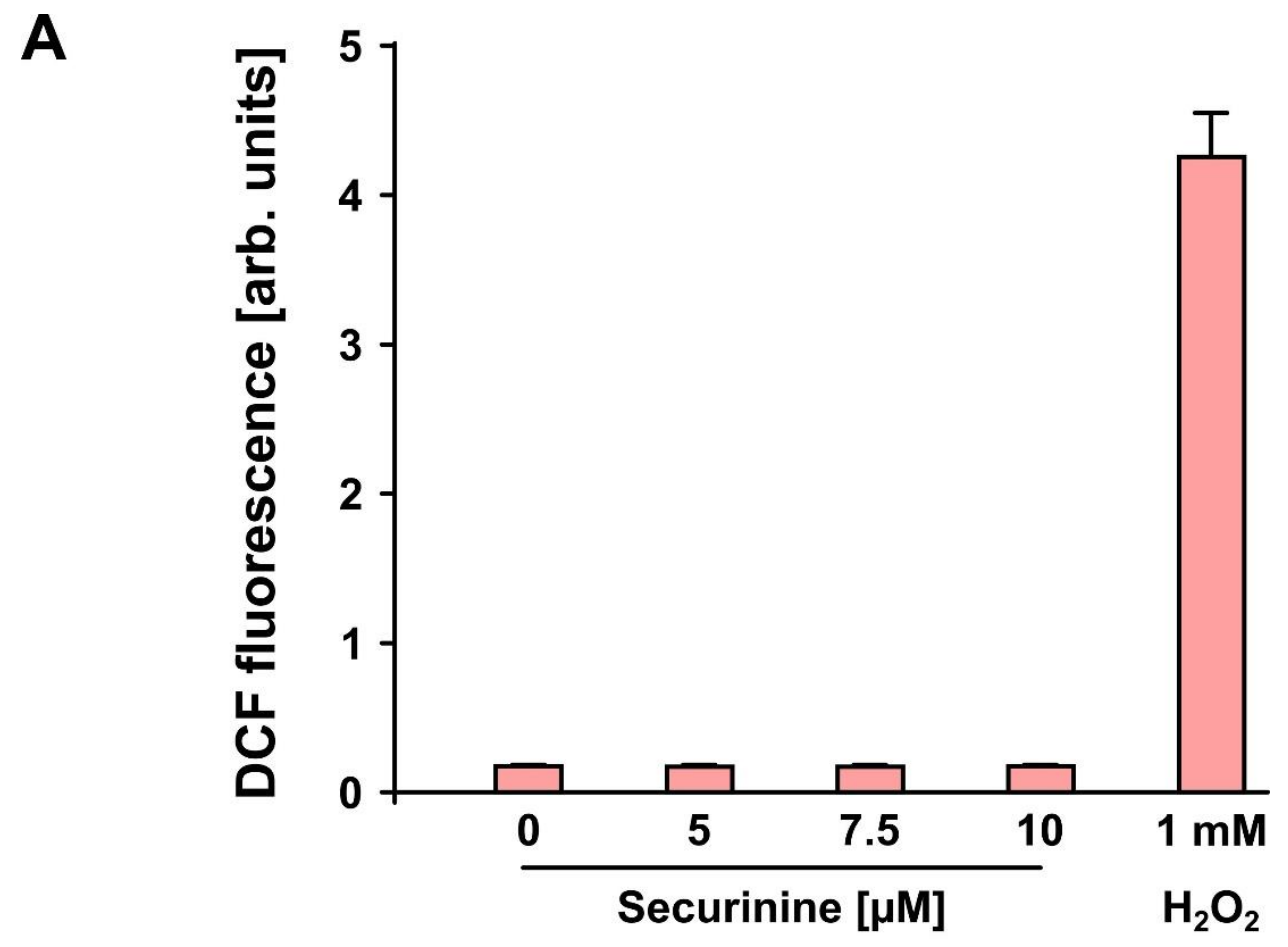

B

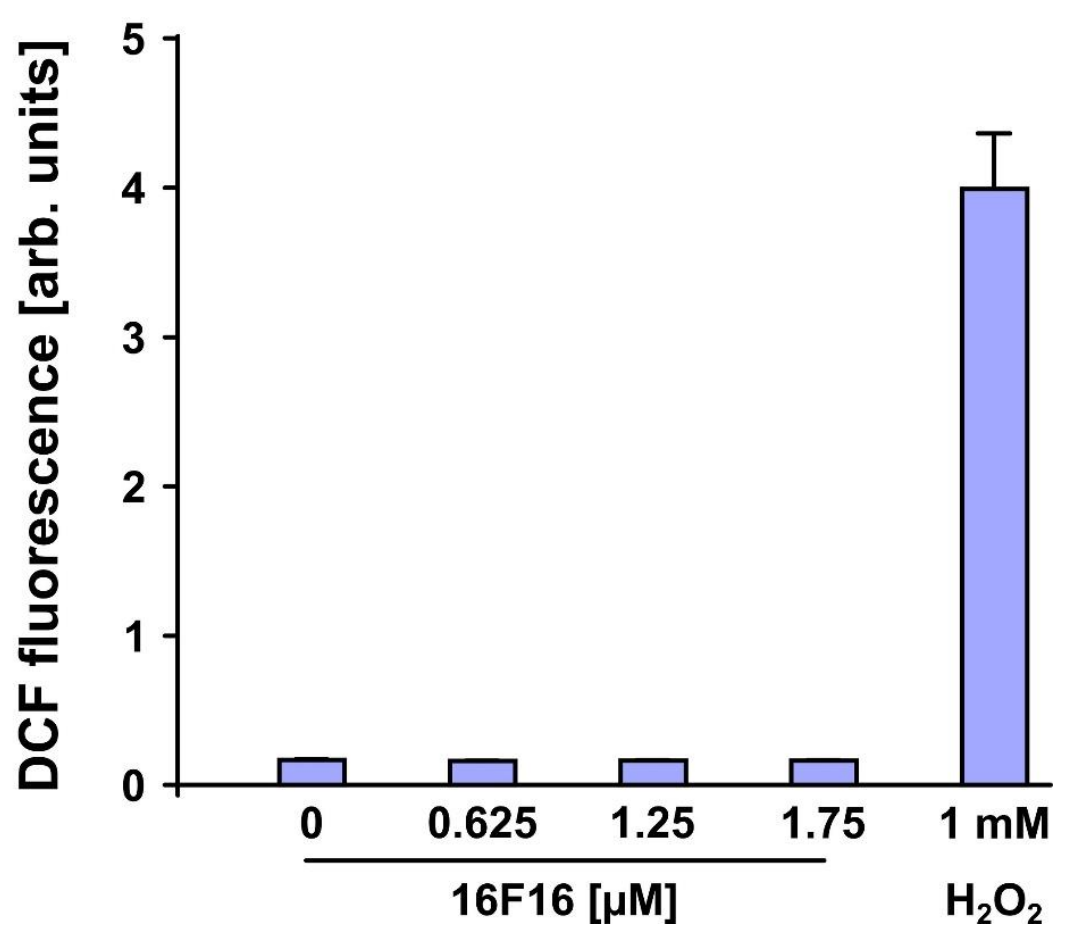

Figure S7. The redox status of SH-SY5Y cells after treatment with either securinine $(\mathbf{A})$ or $16 \mathrm{~F} 16$ (B) was assessed via oxidation of DCFDA. $\mathrm{H}_{2} \mathrm{O}_{2}(1 \mathrm{mM})$ served as positive control. Error bars represent standard deviation of three independent experiments. 
Table S1. Genes with at least 2-fold expression change in both PDI inhibitor treatment regiments

\begin{tabular}{|c|c|c|c|c|c|c|c|}
\hline \multirow[b]{2}{*}{ Gene Symbol } & \multirow[b]{2}{*}{ HGNC Gene Title } & \multicolumn{3}{|c|}{ Securinine } & \multicolumn{3}{|c|}{$16 \mathrm{~F} 16$} \\
\hline & & $\log _{2}$ FC & p-value & $\begin{array}{l}\text { adj. } p- \\
\text { value }\end{array}$ & $\log _{2} F C$ & p-value & $\begin{array}{l}\text { adj. } p- \\
\text { value }\end{array}$ \\
\hline NQO1 & $\mathrm{NAD}(\mathrm{P}) \mathrm{H}$ dehydrogenase, quinone 1 & 3.6476 & 0.0000 & 0.0001 & 2.8131 & 0.0000 & 0.0257 \\
\hline GDF15 & growth differentiation factor 15 & 3.8847 & 0.0000 & 0.0001 & 2.0117 & 0.0000 & 0.0365 \\
\hline FAT1 & FAT atypical cadherin 1 & 2.9316 & 0.0000 & 0.0006 & 1.3823 & 0.0000 & 0.0265 \\
\hline SERPINE1 & $\begin{array}{l}\text { serpin peptidase inhibitor, clade } \mathrm{E} \text { (nexin, plasminogen activator } \\
\text { inhibitor type } 1 \text { ), member } 1\end{array}$ & 2.8454 & 0.0000 & 0.0021 & 1.9800 & 0.0001 & 0.0422 \\
\hline LINC00589 & long intergenic non-protein coding RNA 589 & 2.4933 & 0.0000 & 0.0012 & 1.5690 & 0.0000 & 0.0365 \\
\hline NBPF19 & neuroblastoma breakpoint family, member 19 & 2.4861 & 0.0001 & 0.0042 & 2.8665 & 0.0002 & 0.0496 \\
\hline ID1 & $\begin{array}{l}\text { inhibitor of DNA binding 1, dominant negative helix-loop-helix } \\
\text { protein }\end{array}$ & 2.3000 & 0.0000 & 0.0014 & 1.5191 & 0.0000 & 0.0365 \\
\hline MIR548AL & microRNA 548al & 2.2745 & 0.0000 & 0.0031 & 1.7743 & 0.0000 & 0.0365 \\
\hline TFPI2 & tissue factor pathway inhibitor 2 & 2.0354 & 0.0000 & 0.0012 & 1.1222 & 0.0001 & 0.0415 \\
\hline GCLM & glutamate-cysteine ligase, modifier subunit & 1.9219 & 0.0000 & 0.0012 & 1.1194 & 0.0000 & 0.0365 \\
\hline EDA2R & ectodysplasin A2 receptor & 1.8044 & 0.0000 & 0.0012 & 1.1751 & 0.0000 & 0.0365 \\
\hline ID3 & $\begin{array}{l}\text { inhibitor of DNA binding 3, dominant negative helix-loop-helix } \\
\text { protein }\end{array}$ & 1.5346 & 0.0000 & 0.0029 & 1.3682 & 0.0001 & 0.0368 \\
\hline SQSTM1 & sequestosome 1 & 1.5045 & 0.0000 & 0.0021 & 1.0157 & 0.0000 & 0.0365 \\
\hline RNU6ATAC & RNA, U6atac small nuclear (U12-dependent splicing) & $\begin{array}{l}1.2886 \\
1.1530\end{array}$ & $\begin{array}{l}0.0000 \\
0.0000\end{array}$ & $\begin{array}{l}0.0021 \\
0.0024\end{array}$ & 1.0663 & 0.0000 & 0.0363 \\
\hline LINC00473 & long intergenic non-protein coding RNA 473 & 1.1065 & 0.0001 & 0.0053 & 1.4160 & 0.0001 & 0.0376 \\
\hline KIF1C & kinesin family member $1 \mathrm{C}$ & 1.0780 & 0.0001 & 0.0042 & 1.0096 & 0.0001 & 0.0368 \\
\hline SNORD75 & small nucleolar RNA, C/D box 75 & 1.0057 & 0.0001 & 0.0053 & 1.0175 & 0.0001 & 0.0368 \\
\hline HGF & hepatocyte growth factor (hepapoietin A; scatter factor) & -1.0683 & 0.0012 & 0.0189 & -1.4711 & 0.0002 & 0.0471 \\
\hline ARHGAP36 & Rho GTPase activating protein 36 & -1.1189 & 0.0000 & 0.0024 & -1.0130 & 0.0000 & 0.0368 \\
\hline FGF14 & fibroblast growth factor 14 & -1.1516 & 0.0000 & 0.0028 & -1.2650 & 0.0000 & 0.0365 \\
\hline SNORD72 & small nucleolar RNA, C/D box 72 & -1.1635 & 0.0001 & 0.0060 & -1.0084 & 0.0002 & 0.0422 \\
\hline TSPEAR-AS2 & TSPEAR antisense RNA 2 & -1.2422 & 0.0001 & 0.0048 & -1.3948 & 0.0000 & 0.0363 \\
\hline CHRM3 & cholinergic receptor, muscarinic 3 & -1.2570 & 0.0000 & 0.0033 & -1.0878 & 0.0001 & 0.0408 \\
\hline TSPEAR-AS1 & TSPEAR antisense RNA 1 & -1.4352 & 0.0000 & 0.0031 & -1.7121 & 0.0000 & 0.0335 \\
\hline SERPINF1 & $\begin{array}{l}\text { serpin peptidase inhibitor, clade } F \text { (alpha-2 antiplasmin, pigment } \\
\text { epithelium derived factor), member } 1\end{array}$ & -1.5028 & 0.0000 & 0.0021 & -1.2488 & 0.0001 & 0.0368 \\
\hline PDZRN3 & PDZ domain containing ring finger 3 & -1.5080 & 0.0002 & 0.0072 & -1.0481 & 0.0001 & 0.0421 \\
\hline NEUROG2 & neurogenin 2 & -1.5655 & 0.0000 & 0.0023 & -1.8318 & 0.0000 & 0.0265 \\
\hline PPAP2B & phosphatidic acid phosphatase type $2 B$ & -1.5693 & 0.0000 & 0.0027 & -1.0480 & 0.0000 & 0.0365 \\
\hline LOC100505727 & uncharacterized LOC100505727 & -1.7248 & 0.0000 & 0.0018 & -1.4389 & 0.0000 & 0.0363 \\
\hline INSM2 & insulinoma-associated 2 & -1.9511 & 0.0000 & 0.0012 & -1.4460 & 0.0000 & 0.0365 \\
\hline $\mathrm{CHGA}$ & chromogranin A & -2.0832 & 0.0000 & 0.0019 & -1.3246 & 0.0000 & 0.0265 \\
\hline DDC & dopa decarboxylase (aromatic L-amino acid decarboxylase) & -2.1011 & 0.0000 & 0.0013 & -1.0465 & 0.0002 & 0.0422 \\
\hline MYC & v-myc avian myelocytomatosis viral oncogene homolog & -2.5890 & 0.0000 & 0.0012 & -1.4931 & 0.0002 & 0.0496 \\
\hline MAP2K6 & mitogen-activated protein kinase kinase 6 & -2.6750 & 0.0000 & 0.0023 & -1.1492 & 0.0000 & 0.0365 \\
\hline TXNIP & thioredoxin interacting protein & -3.3847 & 0.0000 & 0.0006 & -1.3395 & 0.0001 & 0.0396 \\
\hline RAB27B & RAB27B, member RAS oncogene family & -3.6471 & 0.0000 & 0.0014 & -2.3015 & 0.0000 & 0.0265 \\
\hline
\end{tabular}


Supplementary Information

Table S2. Selected genes for qRT-PCR validation

\begin{tabular}{|c|c|c|c|c|c|}
\hline \multirow{2}{*}{ Gene Symbol } & \multirow{2}{*}{ HGNC Gene Title } & \multicolumn{2}{|c|}{ Securinine } & \multicolumn{2}{|c|}{$16 \mathrm{~F} 16$} \\
\hline & & $\log _{2} F C$ array & $\log _{2}$ FC qRT-PCR & $\log _{2}$ FC array & $\log _{2}$ FC qRT-PCR \\
\hline NQO1 & $\mathrm{NAD}(\mathrm{P}) \mathrm{H}$ dehydrogenase, quinone 1 & 3.6476 & 3.5889 & 2.8131 & 3.0018 \\
\hline GDF15 & growth differentiation factor 15 & 3.8847 & 5.7024 & 2.0117 & 2.9036 \\
\hline TXNIP & Thioredoxin-interacting protein & -3.3847 & -5.1826 & -1.3395 & -2.1221 \\
\hline INSM2 & insulinoma-associated 2 & -1.9511 & -0.1988 & -1.4460 & -0.4942 \\
\hline MYC & $\begin{array}{l}\text { v-myc avian myelocytomatosis viral } \\
\text { oncogene homolog }\end{array}$ & -2.5890 & -3.6492 & -1.4931 & -2.3464 \\
\hline RAB27B & RAB27B, member RAS oncogene family & -3.6471 & -6.6056 & -2.3015 & -4.3365 \\
\hline
\end{tabular}


Table S3. List of oligonucleotides used in this study

\begin{tabular}{|c|c|c|}
\hline Gene & Direction & Sequence \\
\hline \multirow[t]{2}{*}{ NQO1 } & forward & 5'-CTGCCATCATGCCTGACTAA-3' \\
\hline & reverse & 5'-TGCAGATGTACGGTGTGGAT-3' \\
\hline \multirow[t]{2}{*}{ GDF15 } & forward & 5'-CTCCAGATTCCGAGAGTTGC-3' \\
\hline & reverse & 5'-AGAGATACGCAGGTGCAGGT-3' \\
\hline \multirow[t]{2}{*}{ TXNIP } & forward & 5'-ACTCGTGTCAAAGCCGTTAGG-3' \\
\hline & reverse & 5'-TCCCTGCATCCAAAGCACTT-3' \\
\hline \multirow[t]{2}{*}{ INSM2 } & forward & 5'-TCССТССТСТGАССTCCCGA-3' \\
\hline & reverse & 5'-ATCAGGAGTGGGAGCGGGTC-3' \\
\hline \multirow[t]{2}{*}{ MYC } & forward & 5'-TGCTGCCAAGAGGGTCAAGT-3' \\
\hline & reverse & 5'-GTGTGTTCGCCTCTTGACATT-3' \\
\hline \multirow[t]{2}{*}{ RAB27B } & forward & 5'-TGGCAACAAGGCAGACCTACCA-3' \\
\hline & reverse & 5'-СTCCACATTCTGTCCAGTTGCTG-3' \\
\hline
\end{tabular}




\section{Supplementary References}

1. Özcelik, D.; Pezacki, J. P., Small Molecule Inhibition of Protein Disulfide Isomerase in Neuroblastoma Cells Induces an Oxidative Stress Response and Apoptosis Pathways. ACS Chem Neurosci 2019, 10 (9), 4068-4075.

2. Szklarczyk, D.; Gable, A. L.; Lyon, D.; Junge, A.; Wyder, S.; Huerta-Cepas, J.; Simonovic, M.; Doncheva, N. T.; Morris, J. H.; Bork, P.; Jensen, L. J.; Mering, C. V., STRING v11: proteinprotein association networks with increased coverage, supporting functional discovery in genome-wide experimental datasets. Nucleic Acids Res 2019, 47 (D1), D607-D613. 